\title{
Direct growth of flexible and scalable photocathodes from $\alpha$-brass
}

substrates Sriya Banerjee, ${ }^{a}$ Yoon Myung, ${ }^{a}$ Sankar Raman, ${ }^{b}$ Parag Banerjee*a,c

${ }^{a}$ Department of Mechanical Engineering \& Materials Science, 'Institute of Materials Science \& Engineering, One Brookings Drive,

Washington University in St. Louis, St. Louis, MO 63130, USA.

Physical*Electronics, Chanhassen, MN 55317, USA.

Email: parag.banerjee@wustl.edu

\section{Supplementary Material S1: Oxidation of pristine copper foil}


Figure S1: The oxidation of a pristine copper foil, under atmospheric conditions, results in a composite oxide thickness(excluding nanowire height) of $8.3 \mu \mathrm{m}, 11.67 \mu \mathrm{m}$ and $22.9 \mu \mathrm{m}$ at $400^{\circ} \mathrm{C}, 500^{\circ} \mathrm{C}$ and $600^{\circ} \mathrm{C}$ respectively(indicated by white arrows in figure). 
Supplementary Material S2: Phase separation of copper oxide and zinc oxide in dezincified $\alpha$-brass at higher temperatures $\left(800{ }^{\circ} \mathrm{C}\right.$ oxidation)
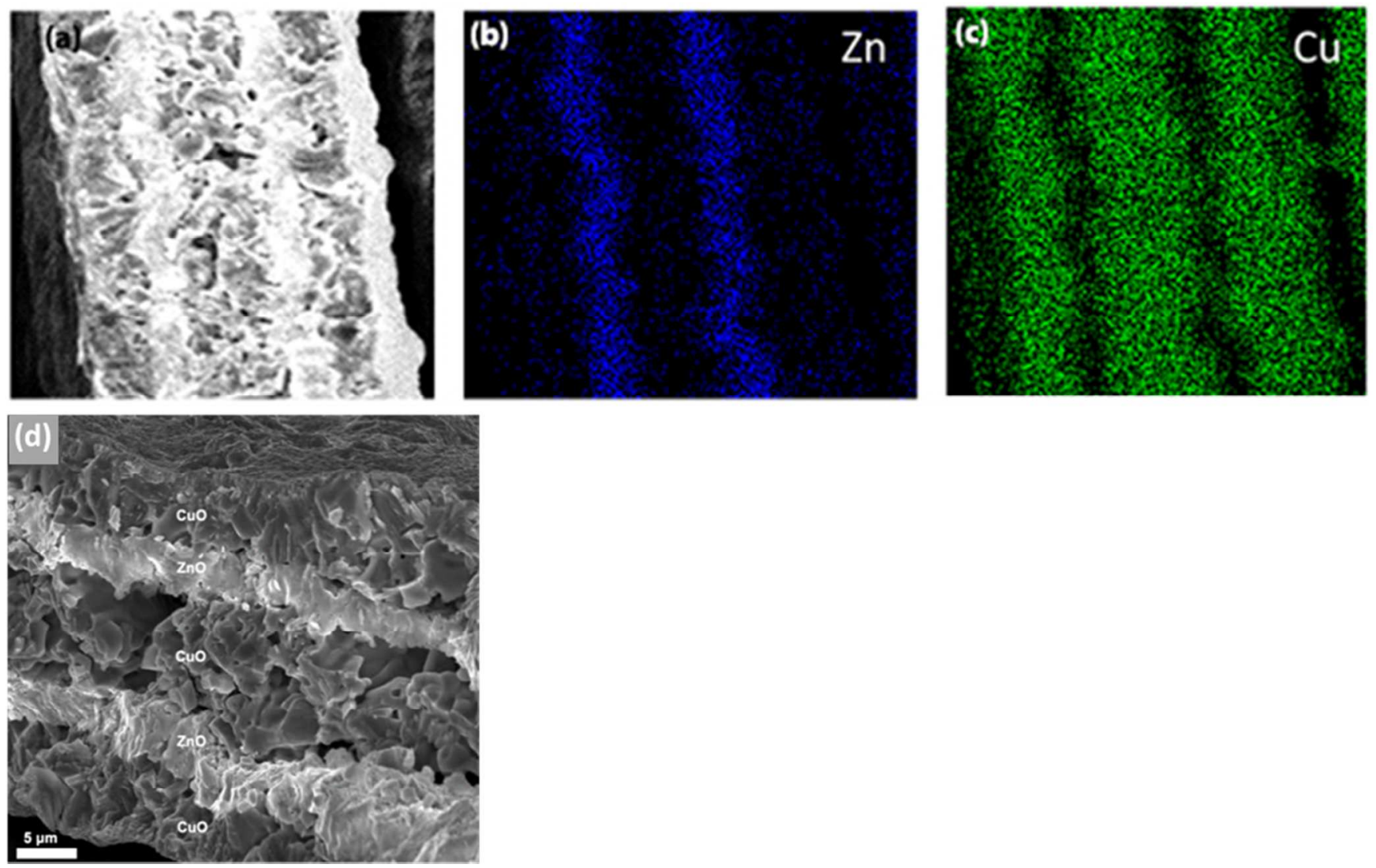

Figure S 2: (a) SEM image of a de-Zn + oxidized brass for 5 hours at $800^{\circ} \mathrm{C}$. (b) EDS map of $\mathrm{Zn}$ (c) EDS map of $\mathrm{Cu}(\mathrm{d}) \mathrm{A} \mathrm{ZnO}$ layer is seen to form below a $\mathrm{CuO}$ oxide scale resulting in a layered $\mathrm{CuO}-\mathrm{ZnO}$ structure. 


\section{Supplementary Material, S3: Raman spectroscopy penetration depth calculation}

The penetration depth of the excitation laser source can be calculated using the equation below, ${ }^{1}$ $\delta=\frac{\lambda_{\text {excitation }}}{4 \pi n k}=\frac{1}{\alpha(\lambda)}$

Here, $\delta$ is the penetration depth (in $\mathrm{nm}$ ), $\mathrm{n}$ is the refractive index and $\mathrm{k}$ is the absorption index

The $\mathrm{n}$ and $\mathrm{k}$ values of $\mathrm{CuO}$ at $514 \mathrm{~nm}$ are approximately ${ }^{3} 2.47$ and 0.65 . This gives a penetration depth of $25 \mathrm{~nm}$ for $\lambda_{\text {excitation }}$ of $514 \mathrm{~nm}$ laser.

\section{Supplementary Material, S4: EDS scan of de-Zn oxidized brass at $500^{\circ} \mathrm{C}$}
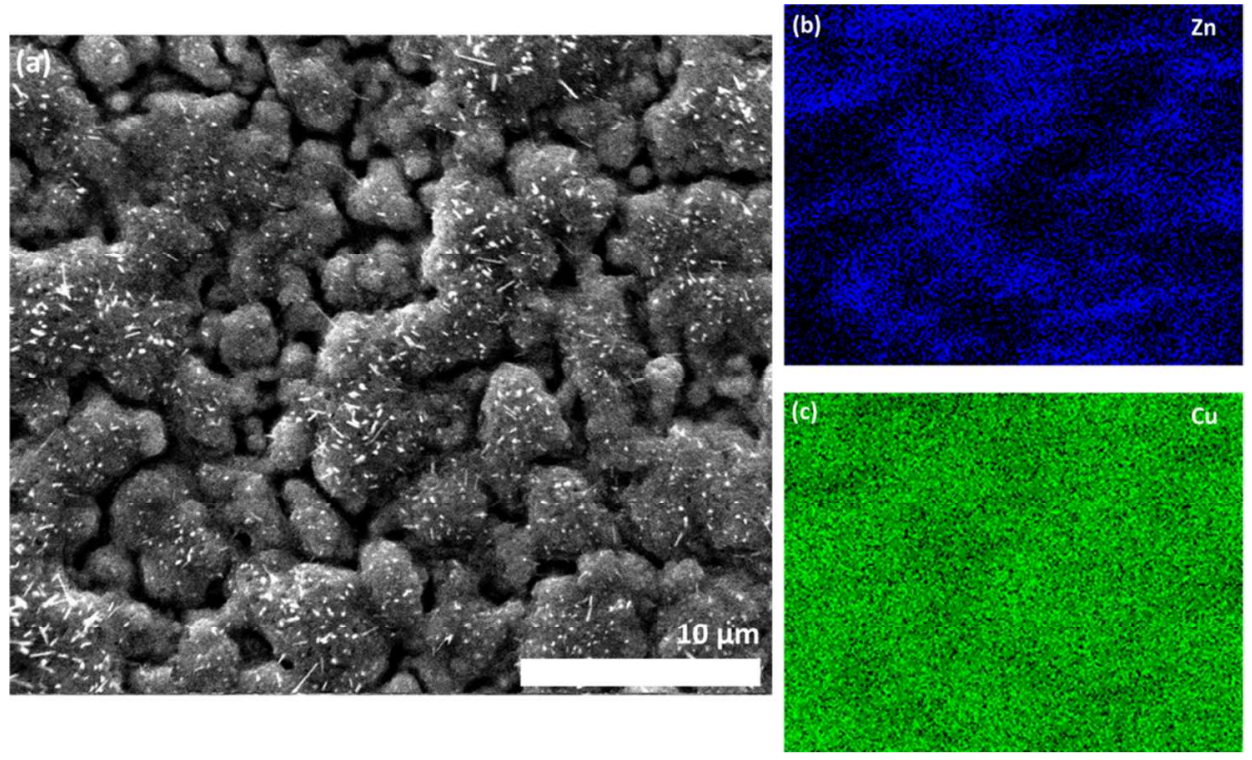

Figure S4 (a) SEM image of de-Zn +oxidized brass at $500^{\circ} \mathrm{C}$. (b)-(c) EDS scan showing Zn and $\mathrm{Cu}$ maps respectively. $\mathrm{Cu}$ is present homogenously whereas $\mathrm{Zn}$ is preferentially distributed in the pores on the surface. 


\section{Supplementary Material, S5: Stability of electrode with 5nm Atomic Layer Deposited}

(ALD) $\mathrm{Al}_{2} \mathrm{O}_{3}$ layer

$\mathrm{Al}_{2} \mathrm{O}_{3}$ films, $5 \mathrm{~nm}$ in thickness was deposited by atomic layer deposition using a home-built ALD system, with trimethyl alumina (TMA) and water as precursors. As a result of the alumina layer deposition, the degradation of the photocathodes was seen to improve from $72 \%$ to $50 \%$ after 20 minutes of testing in chopped light condition.

(a)

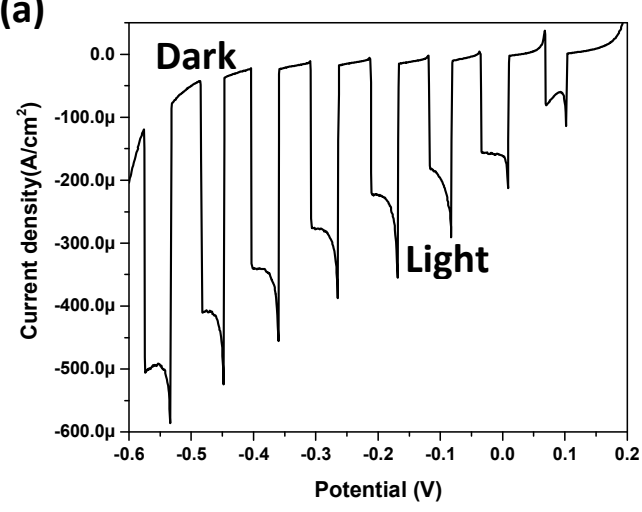

(b)



Figure S 5: (a) Current density vs. voltage of $A L D 5 \mathrm{~nm} \mathrm{Al}_{2} \mathrm{O}_{3}$ coated oxidized brass sample. (b) Chopped light response of $A L D 5 \mathrm{~nm} \mathrm{Al}_{2} \mathrm{O}_{3}$ oxidized brass sample for 20 minutes (1200 seconds). The degradation improved from $72 \%$ in the uncoated sample to $50 \%$ on the coated sample. 


\section{Supplementary Material, S6: Mott-Schottky test of the photocathodes}

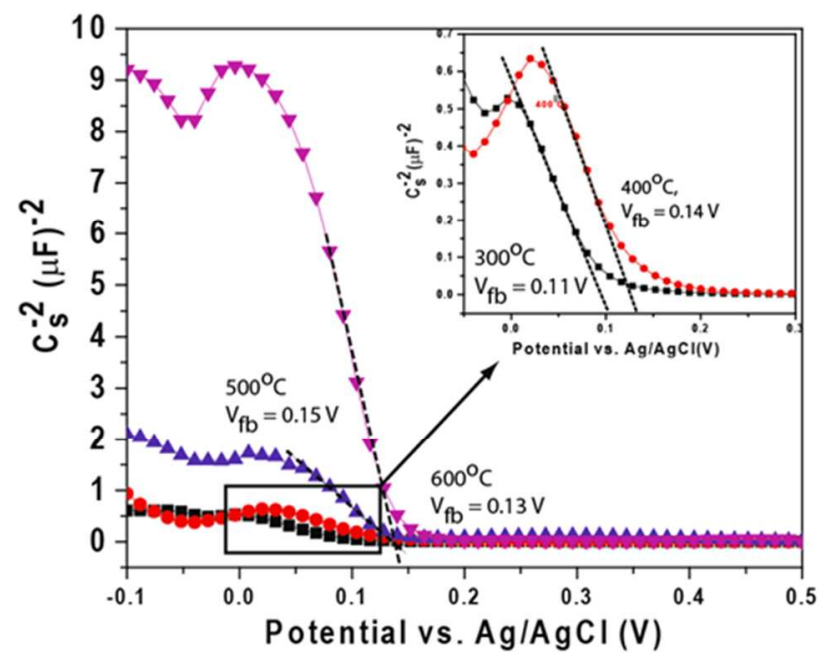

Figure S 6: Mott-Schottky plots for the oxidized samples. The inset shows the flat band potential $\left(V_{f b}\right)$ extrapolation for the $300^{\circ} \mathrm{C}$ and $400^{\circ} \mathrm{C}$ samples.

The plot of $1 / \mathrm{C}^{2} \mathrm{v} / \mathrm{s}$ applied potential $(\mathrm{V})$ should be a straight line with a negative slope for a $\mathrm{p}$ type semiconductor. The abscissa of the $1 / \mathrm{C}^{2}$ plot gives the flat band potential as can be seen from the figure. The plot is however not perfectly linear and this is generally caused due to surface roughness of the samples or the presence of both $p$ and n-type impurities on the surface. ${ }^{2}$

\section{References}

1. Gouadec, G.; Colomban, P. Raman Spectroscopy of nanomaterials: How spectra relate to disorder, particle size and mechanical properties. Prog. Cryst. Growth Charact. Mater. 2007, 53 (1), 1-56. 2. Sharma, D.; Verma, A.; Satsangi, V. R.; Shrivastav, R.; Dass, S. Nanostructured $\mathrm{SrTiO}_{3}$ thin films sensitized by $\mathrm{Cu}_{2} \mathrm{O}$ for photoelectrochemical hydrogen generation. International Journal of Hydrogen Energy 2014, 39 (9), 4189-4197.

3. http://www.ioffe.ru/SVA/NSM/nk/Oxides/Gif/cuo.gif 